Jean-François Hardy MD FRCFC, Gilles Plourde MD FRCPC, Michel Lebrun PH D, Christiane Côté B SC INF, Serge Dubé mD Frcsc, Yves Lepage PH

\title{
Determining gastric contents during general anaesthesia: evaluation of two methods
}

Two methods used to measure the volume of gastric contents were evaluated in 24 supine anaesthetized aduits. Methods compared were: (J) aspiration of stomach cantents through a large, vented, multi-orificed gastric thbe, and (2) indirecr determination by a dye dilution ntethad wsing polyethylene glycol (PEG) as the marker. The volumes determined by these merhods ( $V_{a s p}$ and $V_{\text {peg }}$ respectively) mere compared to the colal wolume ( $V_{\text {nor }}$ ) present in the stomach, desermined by direct inspecion of the gastric pouch by the surgeon at the beginning of surgery. The results show that the volume of aspirated gastric fluid, using this type of tube, is a very good estimate of the total volume of gastric residue. The PEG dilution method yields similar re. sults. However, correlation benween $V_{\text {peg }}$ and $V_{\text {ro }}$ was not as close-fiting as the correlation between $V_{a s p}$ and $V_{\text {ior }} P E G$ dilutian is more complicated, time-consuming and offers no advantage over aspiration.

\section{Key words}

GASTRO-INTESTINAL TRACT: stomach, contents; MEASUREMENT TECHNLOUES: polyethylene glycol.

From the Departments of Anaesthesia, Biochemistry and Surgery, Maisonneuve-Rosemont Hospital, University of Montreal, Montreal, Quebec.

Presented in part at the Canadian Anaestherists" Sociely annual meeting in Montreal, June 1986.

Address correspondence to: Dr. Jcan-François Hardy, Maisonneuve-Rosemont Hospital, 5415 l'Assomption B]vd. Montreal, P.Q., H1T $2 \mathrm{M} 4$.

This work was supported by a grant from the University of Montreal.
Accurate measurement of the volume of gastric contents is of importance to help identify patient populations at increased risk of regurgitation and subsequent aspiration during genteral anaesthesia. Despite numerous studies on the volume and $\mathrm{pH}$ of gastric fluid of different patient populations coming for elective surgery, few authors have attempted to validate their method of quantifying gastric volume. Two methods are readily available in clinical practice to measure this volume: (1) gastric intubation and presumed complete aspiration of fluid contained in the stomach, and (2) indirect determination by a dye dilution method

Both methods have their drawbacks. Aspiration of fluid may be incomplete, especially with conventional Levin tubes. ${ }^{l}$ Dye dilution has been thoroughly investigated in the gastroenterology laboratory. ${ }^{2-3}$ The method has becn shown to be accurate when patients were kept sitting, when the position of the stomach tube used for dye injection and sampling was checked radiologically, and when the previously determined optimal concentrations of indicator dye were used. However, the method has never been validated in the operating room environment. Furthermore, the functional division of the stomach into antral and fundal sacs in supine patients ${ }^{4}$ may interferc with both aspiration and dilution. Thus, we believed that a re-evaluation of these experimental methods was necessary. This study was designed to prospectively validate both gastric fluid measurement techniques in the supine, anaesthetized, patient.

\section{Methods}

The study was approved by the Ethics Committee and informed consent was obtained for all patients. Twentyfour ASA physical status I-III adult patients undergoing elective laparotomy, excluding surgery of the oesophagus and stomach, were studied. The anaesthetics were standardized. Induction consisted of a defasciculating dose of d-tubocurarine (DTC $50 \mu \mathrm{g} \cdot \mathrm{kg}^{-1}$ ), fentanyl $6 \mu \mathrm{g} \cdot \mathrm{kg}^{-1}$, pre-oxygenation with 100 per cent oxygen by face mask for threc minutes, followed by thiopentone $4 \mathrm{mg} \cdot \mathrm{kg}^{-1}$ and succinylcholine $1.5 \mathrm{mg} \cdot \mathrm{kg}^{-1}$. Mask ventilation was avoided to prevent gastric insufflation. The trachea was 
intubated with a cuffed endotracheal tube. Anaesthesia was maintained with nitrous oxide 60 per cent and isoflurane as needed, in oxygen. Patients were paralysed with pancuronium IV.

After the skin incision, but before exploration of the abdominal cavity, an 18 Fr Salem Sump tube (Argyle, St Louis, Mo.) was passed orally into the stomach. Gastric contents were aspirated as completely as possible (aspirated volume: $V_{\text {asp }}$ ), using a $50-\mathrm{ml}$ syringe. The surgeon was then asked to inspect the stomach and ascertain complete gastric emptying. This direct inspection could lead to aspiration of additional gastric fluid" upon mobilisation of the gastric pouch (additional volume: $V_{\text {add }}$ ). The stomach was then retumed to its original position in the abdominal cavity.

In 15 patients, the total volume $\left(\mathrm{V}_{\mathrm{lot}}=\mathrm{V}_{\mathrm{asp}}+\mathrm{V}_{\mathrm{add}}\right)$ less a 2-ml sample used for later determination of gastric $\mathrm{pH}$ was re-injected into the stomach and then diluted with $100 \mathrm{ml}$ of a 0.4 per cent polyethylene glycol (PEG) solution. PEG is an indicator currently used in gastroentcrology to measure the rate of gastric emptying. Mixing of the dye with gastric fluid was achieved by withdrawing the gastric contents into a $50 \mathrm{ml}$ syringe and then reinjecting the fluid. This was repeated five times. The mixture was then re-aspirated as completcly as possible $\left(V_{\text {re-asp }}\right)$. PEG concentrations were determined by turbidimetry, in two $3 \mathrm{ml}$ samples. Knowledge of PEG concentration enabled calculation of the volume diluting the indicator ( $\mathrm{V}_{\mathrm{PEG}}$; Figure 1). The biochemist in charge of determining $V_{\text {PEG }}$ was blinded to $V_{\mathrm{Lo}}$.

In the first nine patients studied, dilution of gastric fluid with only $30 \mathrm{ml}$ of indicator solution led to completely erratic determinations of $V_{P E G}$, which were excluded (see Discussion). After consultation with a gastroenterologist, the method described above was used to determine $V_{\text {PEG }}$ in the remaining 15 patients.

Statistical analysis was performed by the Department of Mathematics and Statistics. Student's t tests for paired data and linear regression analysis were used. A $p<0.05$ was considered significant.

\section{Results}

Aspiration of gastric contents was performed in all 24 patients. The volume of fluid retrieved from the stomach on initial aspiration ( $V_{a s p}$ ) was $31.1 \pm 28.8 \mathrm{ml}$ (mean $S D$ )

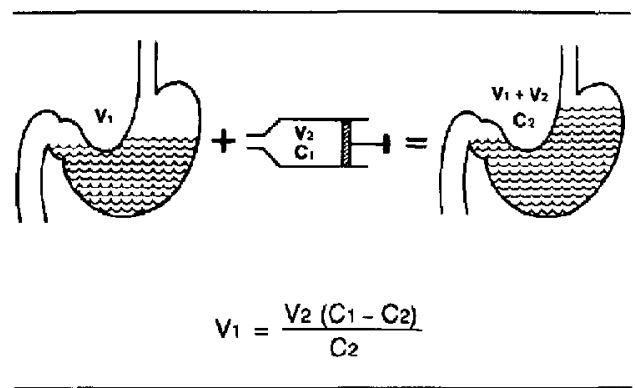

F]GURE 1 Principle of the dye dilution technique. $V_{1}$ (or $V_{\mathrm{PEG}}$ ) is volume of fluid initially present in stomach. $V_{2}$ is volume of indicator dye. $C_{1}$ is initial concentration of indicator dye. $C_{2}$ is final concentration of marker.

and ranged from 0 to $110 \mathrm{ml}$. The additional volume $\left(V_{\text {add }}\right)$ aspirated following direct inspection by the surgeon was $4.4 \pm 3.9 \mathrm{ml}$ (range: 0 to $13 \mathrm{ml}$ ). The total volume $\left(\mathrm{V}_{\text {tot }}\right)$ present in the stomach at the beginning of surgery was $35.5 \pm 29.1 \mathrm{ml}$ (range: 1.5 to $118 \mathrm{ml}$ ). $V_{\text {to }}$ was significantly larger than $V_{\text {asp }},(p<0.0001)$. The volume determined by indicator dilution $\left(V_{P E G}\right)$ in 15 patients was $26.2 \pm 28.8 \mathrm{ml}$. In these 15 patients who had both ceterminations of gastric contents, $v_{\text {PEG }}$ was not statistically different ( $p=0.157)$ from $V_{\text {asp }}(31.2 \pm 27.7 \mathrm{ml})$. Complete results are presented in the Table.

The volume re-injected into the stomach $\left(\mathrm{V}_{\mathrm{tor}}-2 \mathrm{ml}\right.$ for $\mathrm{pH}$ determination $+100 \mathrm{ml}$ PEG solution) was $134.1 \pm 28.2 \mathrm{ml}$. This volume was significantly different from $V_{\text {re-asp }}(122.1 \pm 34.3 \mathrm{ml} ; \mathrm{p}<0.02)$.

There was a statistically significant $(p<0.001)$ correlation between $V_{a s p}$ and $V_{t o t}\left(r=0.99\right.$; Figure 2). $V_{P E C}$ was significantly $(p<0.001)$ correlated to $V_{\text {tot }}(R=0.89$, Figure 3). $V_{\text {re-sp }}$ also significantly $(\mathrm{p}<0.001)$ correlated with the volume re-injected in the stomach $(r=0.87)$.

\section{Discussion}

This study compared two methods of measuring the residual gastric fluid volume in anaesthetized adult patients and validated these methods in relation to actual volumes measured following direct stomach manipulation during laparotomy. The results indicate that volumes determined by both the aspiration and dye dilution methods are satisfactory estimates of the volume of fluid

TABLE Summary of results (mean \pm SD)

\begin{tabular}{lllll}
\hline & $V_{\text {asp }}(\mathrm{ml})$ & $V_{\text {add }}(m l)$ & $V_{\text {rod }}(\mathrm{ml})$ & $V_{\text {PEG }}(\mathrm{ml})$ \\
\hline Initial 9 Patients & $31 \pm 32.2$ & $4.7 \pm 3.5$ & $35.7 \pm 32.6$ & $*$ \\
Subsequcnt 15 Patients & $31.2 \pm 27.7$ & $4.2 \pm 4.3$ & $35.4 \pm 28.1$ & $26.2 \pm 28.8$ \\
Total $(\mathrm{n}=24)$ & $31.1 \pm 28.8$ & $4.4 \pm 3.9$ & $35.5 \pm 29.1$ & $*$ \\
\hline
\end{tabular}

*First nine determinations of $\mathrm{V}_{\mathrm{PEg}}$ were excluded (see text). 


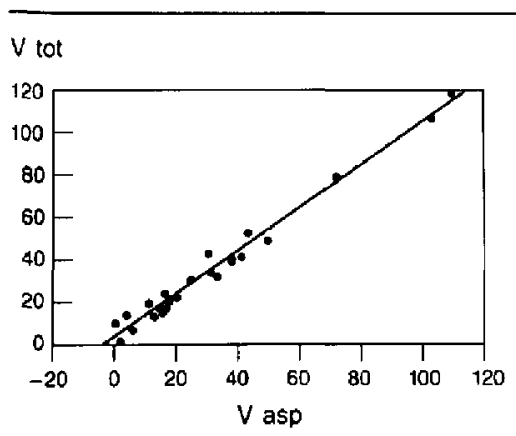

FIGURE 2 Correlation between $V_{\text {asp }}$ and $\left.V_{\text {int }} . V_{\text {tot }}=V_{\mathrm{asp}}+4.3 \mathrm{~m}\right]$ by linear regression analysis ( 24 data points; $r=0.99$ ).

present in the stomach. The correlation with $\mathrm{V}_{\mathrm{tor}}$ determined by aspiration $(r=0.99)$ is slightly better than that determined by PEG dilution $(r=0.89$ ). These data are important since significant medical recommendations have been based on such measurements despite the lack of prior validation.

The principal disadvantages of the aspiration method are that it requires meticulous attention to detail and that there is always a small residue (about $4 \mathrm{ml}$ ) left in the stomach after aspiration. This should not be of major clinical significance.

$V_{\text {re-asp }}$ was significantly smaller than the volume re-injected into the stomach to determine $V_{\text {PEG }}$. This difference may be explained in two ways: either the aspiration tcchnique itsclf was at fault or, alternatively, fluid was lost through the pylorus during the syringing procedure. We believe the latter explanation is morc likely since: (1) the additional volume was very small

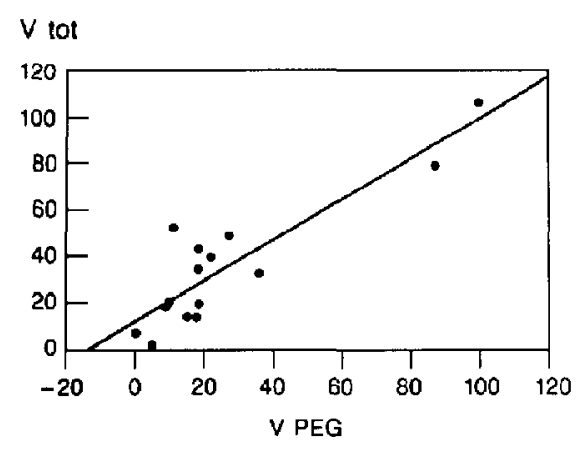

FIGURE 3 Correlation between $V_{\mathrm{PEG}}$ and $\mathrm{V}_{\mathrm{tot}-} \mathrm{V}_{\mathrm{tot}}=0.87 \mathrm{~V}_{\mathrm{PEG}}+$ $12.6 \mathrm{ml}$ by linear regression analysis ( 15 data points; $r=0.89$ ). initially, and (2) $\mathrm{V}_{\mathrm{re}-\mathrm{asp}}$ still significantly correlated with the re-injected volume.

The use of a large more rigid, vented and multi-orificed tube appears to be much more effective than the use of a conventional Levin tube, and this may well explain the discrepancy between this and older ${ }^{1}$ studies. $A$ larger and more rigid tube is easier to position correctly in the stomach, but may be more difficult to pass through the nose. The distal openings of a vented tube will not so readily be obstructed by gastric mucosa. Finally, multiple distal openings spaced on a sufficient length of tubing will ensure that nearly all the gastric pouch is properly drained. The technique is simple, fast and inexpensive. It does not entail the use of ancillary equipment or personnel. This method could also be suitable to cmpty the stomach of its liquid contents prior to anaesthesia.

The gastric volume determined by dye (PEG) dilution is a satisfactory predictor of $V_{\text {Lo, }}$, but $V_{P E G}$ will underestimate $V_{\text {tot }}$ by about $12 \mathrm{ml}$. The method is delicate, complicated and time consuming. Thus, even as a research tool, the technique is not superior to aspiration. It requires homogeneous mixing of gastric fluid and indicator, and a precise determination of PEG concentration. Homogeneous mixing requires a properly positioned tube and an adequate exchange of fluid. The gastric tubes used in this study were most often appropriately positioned in the body ${ }^{2}$ of the stomach, as determined at the time of surgery. Aspiration and re-insertion of five $50-\mathrm{ml}$ syringefuls is a procedure that should ensure adequate mixing (mixing for 30 seconds or more has been found to be adequate $^{2}$ ). The marker used must be non-toxic, watersoluble, non-absorbable and must not be affected by gastric $\mathrm{pH}$.

The validity of PEG as an indicator in the human stomach has been demonstrated. ${ }^{6}$ It is readily measured by a turbidimetric method but this requires the collaboration of experienced laboratory personnel. However, as for other indicators, the behaviour of PEG during initial instillation into the stomach (as compared to subsequent, repeated instillations) raises the possibility that the luminal distribution of indicators may differ from other solutes, such as hydrogen ion, and hence give biased data (spuriously high concentrations). ${ }^{6}$ These falsely elevated PEG concentrations will lead to an underestimation of the volume present in the stomach (Figure 1). The contribution of this phenomenon to our results is not known.

Another possible source of error when determining $V_{\mathrm{PEG}}$ is the loss of stomach fluid through the pylorus during the syringing procedure. This may have occurred, $V_{\text {re-asp }}$ being smaller than the volume re-injected into the stomach. The exact composition of the lost fluid (gastric fluid to indicator solution ratio) will determine the magnitude and direction of the discrepancy between $V_{\text {tot }}$ 
and $V_{P E G}$, but the importance of this possible source of error appears to be minimal when relatively large volumes of indicator solution are used. Conversely, the use of a small volume of PEG solution is less likely to promote adequate mixing and any loss of indicator (or gastric fluid) will result in important variations of $V_{\text {PEG. This could }}$ explain the erratic results observed in our first nine attempts to determine $\mathrm{V}_{\mathrm{PEG}}$.

Division of the stomach into antral and fundal sacs ${ }^{4}$ was shown radiologically to occur in the gas-distended stomach of one female patient. Experiments using an isolated pig's stomach divided by a $35 \mathrm{~mm}$ diameter cylinder to "mimic the effect of the bulge of the vertebral column into a patient's abdomen" showed that a $360^{\circ}$ rotation was needed to ensure adequate mixing of antacid and gastric contents. ${ }^{4}$ While application of these findings to the conditions of the present study is uncertain, we did not encounter any difficulty with aspiration or mixing of gastric fluid and indicator, sccondary to this possible functional division of the stomach.

A previous study ${ }^{5}$ showed the presence of larger volumes of gastric fluid, as determined by a PEG dilution method; when compared to the volumes estimated by aspiration. These results, at conflict with the present report, may be explained by either an incomplete aspiration of gastric fluid using conventional Levin tubes, or by an over-estimation of gastric contents using a PEG dilution method that had not been validated in the anaesthetic setting

We conclude that the volume of aspirated gastric fluid through a large, vented, multi-orificed tube is a very good estimate of the volume present in the stomach at the time of induction in the anaesthetized supine adult patient. The technique is fast, simple and inexpensive. The PEG dilution method does not yield superior results. Furthermore, it is time-consuming, relatively complicated, and requires the use of ancillary equipment and personnel.

\section{References}

1 Holdsworth JD, Furness RMB, Roulston RG. A comparison of apomorphine and stomach tubes for emptying the stomach before general anaesthesia in obstetrics. Br J Anaesth 1974; 46: 526-9.

2 George $J D$. New clinical method for mesasuring the rate of gastric emptying: the double sampling test meal. Gut $1968 ; 9: 237-42$

3 Hurwiz $A$. Measuring gastric volumes by dye dilution. Gut 1981; 22: 85-93.

4 Holdsworth JD, Johnson K, Mascall $G$ et at. Mixing of antacids with stomach contents. Another approach to the prevention of the acid aspiration (Mendelson's) syndrome. Anaesthesia 1980; 35: 64l-50.
5 Ong BY, Palahniuk RJ. Cumming $M$. Gastric volume and $\mathrm{pH}$ in out-patients. Can Anaesth Soc J 1978; 25: 36-9.

6 Ivey KJ, Schedl HP. Gastric nonabsorbable indicators for studies in man. Gastroenterology 1970; 59: 234-9.

\section{Résumé}

Cette étude avait pour but de valider, chez l'adulte antesthésié en décubitus dorsal, deux méthodes de mesure du volume du résidu gastrique couramment disponibles en clinique. (I s'agit de I) l'aspiration directe du contenu gastrique avec une sonde de gros calibre, ventilée et pouvue d'orifices muliples, et de 2) la mesure indirecte du volume gastrique par dilution de l'indicateur potyéthylène glycol (PEG). Les volurres mesurés par ces deux méthodes éraiem comparés au volume absolu présent dans l'estomac déterminé por inspection directe au début de le laparoromie. Nos résulats démontrent que le volume mesuré par aspiration directe, lorsque lon utilise ce type de sonde, est une bonne évaluation du volume du contenu liquide de l' estomac; le sous estimant d' environ $4 \mathrm{ml}$ La méthode utilisant la dilution du PEG fournit également des résultats satisfaisants. La technique est cependant plus campliquée, nécessite la collaboration du laboratoire, et n'offre aucun avantage sur laspiration directe. 